\title{
YAKINSAMA (CONVERGENCE ) VE ÇAPRAZ MEDYA (CROSSMEDIA) STRATEJISININ MEDYA SEKTÖRÜNDE YANSIMALARI ${ }^{1}$
}

\author{
Nurhayat YOLOĞLU
}

\begin{abstract}
Öz
1990’lı yıllara kadar medya sektörünün en önemli sorunlarının başında yer alan, yeni sunucuların medya pazarına girişi gibi sorunların nedenlerinden biri olarak gösterilen teknik engeller, günümüzde taşıyıcı ağların dijitalleşmesi sayesinde ortadan kalkmaya başlamıştır. Bu bağlamda dijitalleşme, çoklu medya ortamlarının gerçekleştiği medya sektöründe yaşanılan büyük değişimlerin temel aktörü olarak değerlendirilebilir. Medya sektörünün yoğun bir biçimde yararlandığı yakınsak teknoloji, kendi içinde yakınsama ve çapraz medya gibi yeni kavramların ve bunlara bağlı stratejilerin gelişmesine katkıda bulunmuştur. Bu çalışmanın amacı Türkçemize "yakınsama" ve "çapraz medya" olarak çevrilen "Convergence" ve Crossmedia" iletişim stratejisi kavramlarının medya sektöründeki yansımalarını incelemektir. Çalışma yöntemi olarak nitel araştırma yöntemi kullanılmış ve betimsel bir çalışma yapılmıştır. Çalışma sonucunda ortaya çıkan bulgulara göre, etimolojik olarak birbirleriyle uyumlu olmayan bu iki kavramın, uygulama alanlarında bazı etiksel ve hukuksal yansımaları bulunduğu, bu çerçevede lehte ve aleyhte bir takım görüşler olduğu saptanmıştır. Örneğin, çapraz medya yakınsamasının aleyhinde olan görüşlerin temelinde; medyada çoklu editoryal yapının, çok sesliliğin kaybına neden olacağı düşüncesi yatmaktadır.
\end{abstract}

Anahtar Kelimeler: Dijital Medya Ekonomisi, Yakınsama, Çapraz Medya, İletişim Etiği

REFLECTIONS OF CONVERGENCE AND CROSS-MEDIA STRATEGIES ON MEDIA

\section{SECTOR}

\section{ABSTRACT}

Technical barriers, which were shown as one of the most important problems of the media sector and one of the reasons of the problems such as the new servers entering the media market until 1990's have started to disappear with the digitalization of the carrier networks. In this context, digitalization can be considered as the main actor of the major changes experienced in the media sector in which multimedia media is realized. Convergent technology, which is used by the media sector extensively has contributed to the development of new concepts such as convergence and cross-media and strategies related to them. The purpose of this study is to examine the reflections of Convergence and Cross-media communication strategy concepts which were translated to Turkish as yakınsama and çapraz medya to media sector. Qualitative research method was used as study method and a descriptive study was conducted. According to the findings of the study, it was determined that these two concepts, which are not etymologically compatible with each other, have some ethical and legal reflections in their fields of application and that there are some favorable and unfavorable opinions within this framework. For

${ }^{1}$ Bu makale 14-17 Mart 2019 Tarihleri Arasında Düzenlenen Uluslararası Türk Dünyası Basın Sempozyumunda Sunulan Bildirinin Geliştirilmiş Tam Metnidir.

2 Dr. Öğretim Üyesi, Ondokuz Mayıs Üniversitesi İletişim Fakültesi Gazetecilik Bölümü, nurhayat.yologlu@omu.edu.tr, ORCID ID: 0000-0002-3392-7326 
YOLOĞLU, Nurhayat (2019). Reflections Of Convergence And Cross-Media Strategies On Media Sector, Gumushane University e-Journal of Faculty of Communication (e-GiFDER) Volume: 7, International Turkish World Press Symposium Special Number, p. 1449-1464

example, on the basis of the views opposing cross-media convergence; lies the idea that multi-editorial structure in the media will cause loss of polyphony.

Keywords: Digital Media Economy, Convergence, Cross Media, Communication Ethics

\section{GiRiş}

Her geçen gün daha fazla yeniliğin yer aldığı medya endüstrisi, aynı zamanda dijitalleşmenin en üst noktada kullanıldığı bir endüstri alanıdır. Analog taşıyıcılardaki enformasyonun bir takım taşıyıcı araçlar vasıtası ile çözümlenip "byt" ve Bit" sayılaştırmalarıyla dönüştürülmesi olarak tanımlanabilecek dijitalleşme, medya sektöründeki birçok soruna da çözüm getirmektedir. Örneğin Dijitalleşme sayesinde yerleşik pazar yapısı kırılmıştır. Taşıyıcı ağların dijitalleşmesi nedeniyle televizyon sinyallerinin yayılmasındaki birçok teknik darboğaz ortadan kalktığı gibi, taşıma kapasitelerinin genişlemesi nedeniyle yeni sunucuların medya pazarına girişindeki engeller de azalmaktadır.

Dijitalleşme internet temelinde gerçekleşirken, özel ve kamusal yaşantımızda sürekli artan bir biçimde yer almaya devam etmektedir. Medya işletmelerinde 1993 yılında dünyada \%3 olan dijitalleşme oranı henüz 2007 yılına gelindiğinde \% 97'ye çıkmıştır (Schneider, 2013: 10). Dijitalleşme yoluyla mevcut pazarın yapısı değişmiş, sadece televizyon, radyo, gazete gibi tekli medyanın yerini çoklu medya ortamları almaya başlamıştır. Medya endüstrisindeki gelişimler, medya işletmecileri için cep telefonu alıcılarına yönelme ihtiyacını ve bu pazardaki araştırma potansiyelini ortaya çıkarmıştır.

2013 y1lında medya sektöründe sosyal medya, veri gazeteciliği, transmedya gibi gözde kavramlar, gazeteciliği ve kurgusal medyayı kökten değiştirmiştir. Periscope veya Bambuser üzerinden canlı video aktarımları (Livestreaming), üç boyutlu haber oyunları (Newsgames), artırılmış gerçeklik (Augmented Reality) gibi dijital gelişimler medya alanında hiç durmayan girişimciliğe örnek verilebilecek gelişmelerdir.

2015 yılında medya dünyası çok daha farklı görünmeye başlamıştır. Artık enformasyon, iletişim ve aktarım teknolojisi gibi tamamen farklı yeniliklerden söz edilmektedir. Örneğin Mikrosoft'un sanal gerçeklik gözlüğü (HoloLens), telefonla 
eşleştirilebilen akıllı saatler (AppleWatch) gibi giydirilebilen (Wearables ) teknoloji piyasaya girerken medya devrimleri durmak bilmemektedir.

Multimedya, Grossmedya, Transmedya gibi kavramlar hem gazete editörlüğü ve röportajlarında, hem de radyo, televizyon, sinema, oyunlar, kitaplar ve sosyal medya gibi kurgusal alanlarda sürekli büyümektedir. Artık senaryo yazılmadan önce tüm hikaye dünyasına ulaşılmakta, kurgusal ve kurgusal olmayan çizgide oyunlar oluşturulmaktadır. $\mathrm{Bu}$ arada medyanın kullanım davranışları da değişmektedir. Almanya, Amerika Birleşik Devletleri, Brezilya, Çin, Hindistan ve Güney Kore’de 7278 kullanıcı üzerinde yapılan araştırmalar, enformasyon ve iletişim teknolojilerinin internet ve yeni medya kullanıcılarının yaşam alanlarının tümünü değiştirirken, diğer yandan yeni ihtiyaçları ortaya çıkardığ 1 sonucunu vurgulamaktadır (Picot vd., 2015: 22). Örneğin smart televizyonlarda olduğu gibi sosyal ağlar televizyonla birleştirilmekte, enformasyonun artan rolü, akıllı telefonlarla başka bir boyuta geçmektedir.

Günümüzde medya endüstrisinde en çok tartışılan konuların başında, radyo alıcısının, televizyonun, telefonun, internet ve bilgisayarın teknik olarak birleşmesi, bir araya getirilmesi anlamında kullanılan yakınsak teknolojiler ve medya sektöründe çapraz medya sahipliğinin vurgulandığı çapraz medya stratejisi kavramları akla gelmektedir. Bu çalışmada öncelikle kavramsal olarak yakınsama ve çapraz medya stratejileri üzerinde durulmakta, buna bağlı olarak bu kavramların ortaya çıkardığı sorunlara dikkat çekilmektedir.

\section{Yakınsama Kavramı}

Türkçemize "yakınsama" olarak çevrilen "convergence" kavramı ekonomi, fizik, matematik, medya başta olmak üzere birçok bilim alanında kullanılmaktadır. Konumuz itibari ile yakınsama kavramı; farklı kullanım anlamları ve medya alanında kullanımı olmak üzere iki ayrı başlık altında açıklanmaya çalışılmıştır.

\subsection{Farklı Kullanım Anlamları Ile Yakınsama Kavramı}

Genel olarak farklı noktaların birbirine yaklaşması ya da entegre olması biçiminde tanımlanabilecek olan yakınsama kavramı daha çok ekonomi, fizik, fen, 
doğa bilimleri, matematik, telekomünikasyon ve medya sektöründe kullanılan bir kavramdır.

Ekonomide "yakınsama" kavramının çıkış noktası 1960 sonrasına dayanan, Abramovitz'in "Belli koşullar altında geride kalmak başlangıçtaki liderden daha hızlı büyüme kabiliyeti ve üretkenliği yaratır" ana düşüncesinden yola çıkılarak oluşturulmuştur (Ceylan, 2010: 150). Benzer tasarruf ve yatırım oranlarına sahip iki ülkeden, başlangıç ekonomik düzeyi düşük olanın daha çok ilerleme, büyüme oranı yaşayacağını öngören ekonomik bir terimdir.

Fizik ve Matematik alanında yakınsama, Türk Dil Kurumu Sözlüğüne göre “Aradaki açıklık sonsuz küçülerek fakat kesişmeden bir noktaya, bir sınıra doğru yaklaşma” (TDK, 2018) olarak tanımlanmaktadır. Gözlük teknolojisinde ise, bir merceğin metre cinsinden odak uzaklığının tersi, o merceğin yakınsaması olarak anlaşılır ve yakınsama birimi, SI birim sisteminde "diyoptri" ile ifade edilir (https://fizikolog.net/konular/optik-1.isik-ve-golge/mercekler.html).

Telekomünikasyon alanı, son yıllarda yakınsama kavramının en çok kullanıldığg alan olmuştur. Buna göre Blakman, "telekomünikasyon ve görsel-işitsel sektörleri etkileyen; teknoloji, hizmet, endüstri yapısı ve hükümet politikalarında çeşitli değişim trendleri” olarak yakınsamayı tanımlar (Karınca, 2013: 263). Medya sektörü dijital alt yapı teknolojisini kullandığı için telekomünikasyona dayanan bakış açısı medya sektörü için de geçerlidir.

\subsection{Medya Sektöründe Yakınsama}

Günümüzde yakınsama teknolojisi ile radyo alıcısının, televizyonun, telefonun, internet ve bilgisayarın teknik olarak birleşmesi, bir araya getirilmesi anlaşılmaktadır. 2006 yılında ilk baskısı yayınlanan iletişim ve medya bilimi adlı sözlükte Marcinkowski, "Elbette teknik açıdan mümkün olan yakınsama gelişmesinin, sosyo-kültürel olarak şekillenen kullanım alışkanlıkları üzerinde hakim olup olmayacağını çok uzun bir süre daha bilemeyeceğiz” (Behmer, 2015: 24) söyleminin üzerinden çok kısa bir süre geçmesine rağmen yakınsama teknolojisinin bütün dünyada büyük bir hızla benimsendiği gözlenmiştir. $\mathrm{Bu}$ bağlamda, bugün dünya nüfusunun \%96's1 mobil telefon kullanmaktadır. İnsanların \%72'si sürekli 
çevrimiçi olup, doğum tarihi 1980- 1999 olan Y kuşağı dünya nüfusunun \%31'ini, Türkiye nüfusunun \%33'ünü kapsamaktadır. Günde 6-8 saat arası ekran karşısında bulunulmakta, \%89 oranında sosyal medya aktif olarak kullanılmaktadır. Türkiye'de Y kuşağının \%87'sinin Facebook hesabı vardır. \%55'i çeşitli markaların web sitelerini takip etmekte ve 10 yıl içinde ana müşterilerin \%80’inin Y kuşağı olacağ varsayılmaktadır (Kıraç, 2018).

Avrupa Komisyonu'nun 1997 tarihli Yeşil Belgesinde yakınsama; farklı şebeke platformları aracılığıyla benzer hizmet çeşitlerinin taşınması ya da telefon, televizyon ve kişisel bilgisayar gibi tüketici aygıtlarının bir araya getirilmesi olarak ifade edilmektedir (https://ec.europa.eu/digital-single-market/en/news/green-paperconvergence-telecommunications-media-and-information-technology-sectors-and).

OECD’nin "Bilgi Ekonomisi Çalışma Grubu” nun 2007 yılında hazırladığı "İnternet Ekonomisi” raporunda yakınsama tanımı ise şöyledir (http://www.oecd.org/officialdocuments/publicdisplaydocumentpdf/?cote=DSTI/ICC P/IE(2007)3/FINAL\&docLanguage=En) :

"Yakınsama, bütün hizmetlerin belirlenmiş olan, sabit, mobil, kablo TV, IP gibi şebeke ile verildiği yapıdan, tüm iletişim hizmetlerinin çeşitli şebekeler üzerinden, kopukluk olmadan ve birçok platform üzerinden interaktif bir biçimde verilmesine doğru bir geçiştir”. Bu bağlamda yakınsama, akıllı telefonlarda resim, video, sinema, radyo, dergi bulunması ve aralarındaki uzaklığın gittikçe azalması, farklı cihazlarda yapılan işlerin gittikçe gelişen teknoloji sayesinde tek bir cihazla yapılabilmesidir. Örneğin; cep telefonlarımız sadece bir iletişim aracı olmaktan çıkmış, kamera, saat, takvim, kronometre, pusula, video oynatıcı, vb. şeyleri de kapsayan bir kompleks haline gelmiştir.

Yakınsama sonucunda 3 çeşit eğilim ortaya çıkmıştır (Özel, 2011: 60): 1.Teknolojik yakınsama, 2. Kurumsal yakınsama, 3. Kullanımın yakınsaması. Teknolojik yakınsama, bilgisayar teknolojisi desteği ile çoğaltılabilen, değiştirilebilen ve depolanabilen sayısal sinyallerin taşındığı sanal iletişim ağlarının birbirine dönüşümünden kaynaklanan yapılanmadır. Buna en iyi örnek akıllı telefonlardir. 
Kurumsal yakınsama denildiğinde, birbirinden farklı teknoloji platformları üzerinde medya içeriğini sunmayı kolaylaştırmak için çapraz mülkiyet ilişkilerini de içine alan medya organizasyon yapısının ortaya çıkması anlaşılmaktadır. 1990 yılından bu yana medya sahipliğinde daha büyük olmak için, market gücünü kullanarak küçük medya şirketlerinin büyük olanlar tarafından satın alınmasına doğru hızla ilerleyen küresel bir eğilim görülmektedir.

Kullanımın yakınsaması ifadesi, tüketicilerin farklı medya araçlarını birlikte kullanması anlamını içermektedir. Burada kullanıcılar, bir başka deyişle tüketiciler, aynı anda birden çok medyadan ve dijital özelliklerden yararlanarak kolayca içerik üretebilirler. Kullanıcıların ürettikleri bu içeriğe "kullanıcı türevli içerik" denir (Binark, 2013: 165).

Yakınsama konusunda bir başka sınıflandırma, geçirilen evrime göre yapılan sınıflandırmadır. Özel'e göre (2011: 61) yakınsama evrimi farklı seviyelerde gruplandırılabilir:

1. Ağ yakınsaması: IP tabanlı geniş bant ağlar tarafından meydana gelir. Sabit-mobil yakınsamasını ve mobil telefon, TV ve bilgisayar gibi 'üç ekran yakınsamasını' içerir.

2. Hizmet yakınsaması: web tabanlı uygulamalara erişim ve cihazların çeşitlenmesi ile geleneksel ve yeni değer kazanmış hizmetlerin hazırlanmasına izin veren yenilikçi el cihazları ve ağ yakınsaması içinde gelişmektedir.

3. Endüstri-Pazar yakınsaması: daha önce farklı pazarlarda olan bilgi teknolojileri, haberleşme ve medya gibi benzer alan endüstrilerini bir araya getirir.

4. Yasama, enstitü ve düzenleyici yakınsaması: mecralar arasında işbirliği, yayıncılık ve haberleşme düzenlemeleri oluşturulur. İçerik ve hizmetlerin sağlandığ1 ağlardan (teknoloji yansız düzenleme) bağımsız, kanuni olarak yakınsak düzenlemeler göz önünde bulundurulur.

5. Cihaz yakınsaması: günümüzde mikroişlemci, ekran, depolama ve giriş elemanları gibi çoklu işlemler sağlayan araçlar yaygındır ve bunlar bazı tür ağ bağlantıları içerir. Artan bir şekilde bunlar çoğul iletişim fonksiyonları ve uygulamaları sağlar. 
6. Yakınsak kullanıcı tecrübeleri: son kullanıcılar yeni medya ve bilgisayar teknolojileri arasında bir ara yüz haline gelebilmektedir.

Medya yakınsaması üzerine kurulan teoriler, ikame, medyanın tamamlanması ve medya birleşmesi olmak üzere üç başlık altında toplanabilir. İkame teorisine göre, yeni medya eski medya tiplerinin yerini alacak ve onların fonksiyonların üstlenecektir. Medyanın tamamlanması teorisi, yeni medyanın uyumlu bir biçimde geleneksel medyayı tamamlayacağını öne sürer. Medya birleşmesi teorisi ise yeni ve geleneksel medyanın tüm özellikleri ile birlikte bir potada birleşeceği savını öngörmektedir (Özel, 2011: 61).

Günümüz uygulamalarına bakılacak olursa, üç kuramın da geçerli olduğu ancak çapraz medya birleşmelerini içeren üçüncü kuramın üzerinde daha çok konuşulduğu söylenebilir.

\section{2. Çapraz Medya Kavramı}

Çapraz medya kavramı, çeşitli içerik, tasarım ve editoryal olarak birbiri ile bağlantılı kanallar aracılığıyla kurulan iletişimi ifade etmek için kullanılır. Bu iletişim türü, kullanıcıyı çeşitli ortamlarda amaçlı olarak yönlendirir ve bir geri bildirim kanalını tanımlar. Çapraz medya kavramı başlangıçta masaüstü yayıncılık alanında kullanılmıştır. Masaüstü yayıncılık, kitap, broşür, dergi veya katalog gibi yayınların metin ve resimlerinin bilgisayar destekli olarak oluşturulmasına verilen addır (https://www.turkcebilgi.com/masaüstü_yayınclık). Grafik tasarım odaklı masaüstü yayıncılığın kalbinde, grafiksel kullanıcı arabirimi olan bir bilgisayar, bir mizanpajın görsel oluşturma yazılımı ve bir dijital baskı şablonunun bir yazıcıya çıkışı yer almaktadır.

Günümüzde çapraz medya kavramı masaüstü yayıncılığın çok ötesinde anlamlar içermektedir. İkinci nesil internet hizmetlerini, toplumsal iletişim sitelerini, vikileri, iletişim araçlarını, internet kullanıcılarının ortaklaşa ve paylaşarak yarattığı sistemleri kapsayan web 2.0 ile birlikte çapraz medya algısı da değişmiş̧tir. Bugün çapraz medya denilince, sanal gerçeklik, görsel müzik, YouTube, Google ve Facebook gibi uygulamalar, sesli mesajlar içeren yeni sosyal ve görsel medya başlıkları, içeriği üretmek ve dağıtmak için kullanılan çeşitli yollar akla gelmektedir. 
Kültürel alanda veya medya sektöründe çapraz medya stratejilerinin kullanımı, giderek artan şekilde görsel ve katılımcı medya kullanımının toplumsal önemini anlamayı gerektirir. Çapraz medya ayrıca katılımcı ve yakınsama kültürü, dijital medya okuryazarlığı, medya yakınsama stratejileri, transmedya hikaye anlatımı, medya hukuku, bilişim hukuku, çapraz medya yönetimi, çapraz medya pazarlaması ve alanındaki yeni gelişmeleri bir araya getirir. Medya kuramları için önemli etkiler oluşturur.

Çapraz medya kavramı aynı zamanda, dağıtım politikasıyla bağlantılı olarak, çok kanallı pazarlamada farklı son kullanıcılara ulaşabilmek için çeşitli dağıtım kanallarındaki ürün veya hizmetlerin paralel dağılımı anlamında da kullanılmaktadır. Pazarlama bağlamında çapraz medya kavramı, bir kampanyanın iletişim karmasını ve çoklu araçların paralel ağ bağlantılı kullanımına işaret eder (Yılmaz ve Erdem, 2016: 192). Bununla pazarlama organizasyonu içerisindeki dağıtım politikası (veya pazarlama karması) ve tedarikçiden müşteriye veya kullanıcıya uzanan süreçte bir ürün veya hizmet yolu ile ilgili tüm kararlar ve satış faaliyetleri şekillendirilir. Ancak burada satış stratejisi ile satış sürecinin tasarlanmasını içeren lojistik (nakliye ve depolama) arasındaki ayrımı göz ardı etmemek gerekir (Schneider, 2013: 16).

Çapraz medya ifadesi, iletişim politikası çerçevesinde kullanılır. Çapraz medya iletişiminin özelliği sadece farklı iletişim kanalları üzerindeki bir reklam mesajının iletilmesi değildir. Burada reklam mesajını veya ilgili ürünü etkileşimli olarak ele almak ve tanımlamak için müşteriye, alıcılara veya tüketicilere yönelik en az üç ortamın sunulmasını sağlayacak şekilde tasarlama yapılır. Seçilen iletişim araçları, içerik, biçim ve zaman açısından çapraz medya kampanyasıyla bütünleştirilir. Buna göre içerik entegrasyonu (kurumsal logo, yazı karakteri ve benzeri içeriklerin bütünleştirilmesi), tüm medya kanallarında tutarlı bir mesajın iletilmesini sağlar. Zamansal bütünleştirme, reklam mesajını güçlendirmek için tüm iletişim araçlarının zamansal kullanımı ve koordinasyonunu içerir (Mahrdt, 2008).

Çapraz medya kavramının kullanıldığı bir başka alan gazeteciliktir. Kavram ilk olarak çevrimiçi gazetecilikte geliştirilmiştir. Bugün gazeteciliğin bütün alanlarında çapraz medya tasarımı kullanılmaktadır. Örneğin bugün www' de temsil edilmeyen pek bir basın ürünü yoktur. Mali açıdan güçlü ulusal basın markaları aynı 
zamanda ya televizyon ve radyo formatları üretirler ya diğer kanallarla işbirliği yaparlar ya da kendi radyo ve televizyon kanallarını işletirler. Yazılı medya çeşitleri, radyo, televizyon, web ve cep telefonları teknik, ekonomik, üretimsel, içeriksel ve fonksiyonel olarak yakınlaşmıştır. Bu bağlamda çapraz medya, üretim, içerik ve marka olmak üzere kabaca üç düzlemde değerlendirilebilir.

Örneğin üretim düzleminde içerik araştırma ekibi; yazılı medya, televizyon ve internet gazeteciliğinde bilginin değiş tokuşundan, editoryal sürece kadar olan süreçte, ortaklaşa çalışarak sinerji yaratırlar. İçerik düzleminde günlük aktüel olayların hikâyeleri, bir medya kuruluşuna bağlı farklı iletişim araçlarında, farklı formatlarda, daha çok araç üzerinden yeniden üretilirler. Marka düzleminde ise gazetecilik markalarının yeni medya alanlarında genişletilmesi yoluyla inanılırlık ve güven transferi oluşturulabilir (Schneider, 2013: 16). Yakınsama teknolojisi sayesinde, gazeteciler ürettikleri içerikleri çıktı ortamından bağımsız yönetebilirler. Medya ürünlerinin hem baskı hem de çevrimiçi olarak çıktısı alınabilir. Ses çıkışı olarak radyoda okunabilir. Bu nedenle günümüzde gazeteciler daha çok çoklu medya veya platformlar için çalışırlar.

Yakınsama teknolojisinin gelişmesi medya ekonomisi için itici bir kuvvet oluşturmuş, çapraz medya stratejileri daha fazla medya işletmeleri tarafindan tercih edilir hale gelmiştir. Bu bağlamda medya ekonomisinin dört önemli bileşeni, medya işletme sahipleri, tüketiciler, reklamcılar ve medya çalışanlarıdır (Kuyucu, 2014: 25). Günümüzde sözü edilen bu dört başrol oyuncusunun kendi içinde yaşadığı rekabetin sonuçları ve medya ekonomisinin geleceğine etkisi daha fazla tartışılmaya başlanmıştır. Kuyucu (2014) çalışmasında, medyanın dört başrol oyuncusundan biri olan reklamcıların medya sektöründe en etkin faktör olarak algılandığını belirtmektedir.

\section{Yakınsama Ve Çapraz Medya Stratejisinin Medya Sektörüne Yansımaları}

Çapraz medya, medya işletmelerinin stratejik bir kararıdır ve yakınsamanın bir üst kavramıdır. Günümüzde yakınsama teknolojisini kullanan çapraz medya, medya işletmeleri için tartışılan bir seçenek değil; bir gereklilik olarak görülmektedir (Behmer, 2015: 40). Görünüş itibari ile çapraz medya stratejileri reklam kombinasyonlarının bir sunumu olarak görülebilir ancak bu çok dar bir yaklaşımdır; 
çünkü çapraz medya kavramı altında, marka transferlerinin tutarlı değişimi de anlaşılabilmektedir. Buna örnek olarak Almanya'nın ünlü dergisi der Spiegel verilebilir. Der Spiegel adı altında hem basılı bir yayın hem de Spiegel TV adlı bir web televizyonu bulunmaktadır.

Esasen çapraz medya stratejisi, farklı medya pazarlarının birbiri ile dokunması ve işlenmesi ile sinerji yaratılması düşüncesi temel alınarak oluşturulmuştur. Çapraz medya alanında; pazara, pazarlamaya, kuruluşa, değer artışı ve çeşitlendirmeye yönelik bakış açıları geliştirilmiştir. Günümüzde editörler ve gazeteciler daha çok çapraz medyayla çalışmayı tercih etmektedirler çünkü böylece bazı kitlelere daha iyi ulaşılabilmekte veya bazı konularla daha iyi ilgilenmekte; daha kapsamlı bilgi verebilmekte; okuyucu, dinleyici veya kullanıc1larla diyaloga girmekte; içeriğgi birden çok kanal üzerinden sunmaktadırlar. Ayrıca eğer belli bir kanal engellenirse, diğer alternatifleri kullanabilme şansları da bulunmaktadır.

Türkiye'de, telekomünikasyon sektörünün devlet tekelinden ayrılması, sektöre yeni oyuncuların girmesine ve rekabete zemin oluşturarak, yakınsama teknolojisinin önünün açılmasına zemin oluşturmuştur. Bu teknolojik gelişmeler telekomünikasyon, medya ve bilişim teknolojilerini birbirlerine yaklaştırmakla kalmamış, sadece geleneksel anlamda altyapı ve buna bağlı olarak hizmet veren oyuncuları da dişarıda bırakmıştır.

Yakınsama teknolojisi sayesinde içerik sağlayıcılar, farklı altyapıları seçebilmekte ve uygulamacılar da daha fazla reklam geliri elde edebilmektedirler. Örneğin bir yapım şirketi, bir dizinin belirli bir sezonun gösterimi için bu diziyi uydu yayını vasıtasıyla ya da IP şebekesi vasıtasıyla televizyonda gösterebileceği gibi, internet üzerindeki belirli bir siteden de yayınlatabilmektedir. İnternet sağlayıcısı dizinin başlamasının öncesine, dizi arasına ya da sonrasına reklam koyarak, reklam geliri de elde edebilmektedir (Karınca, 2013: 273). Özellikle son yıllarda kullanıcı sayılarını hızla arttıran Instagram, Youtube gibi sosyal ağlar da ürün yerleştirme uygulamaları için önemli mecralar haline gelmişlerdir (Bolat, 2018: 34).

Günümüzde çapraz medya yakınsama pazarında dikey, yatay ve karma alanda bütünleşmeler görülmekte; aynı zamanda ara katmanlardaki küçük tedarikçiler de 
varlıklarını sürdürebilmektedir. Örneğin mobil şebekesi aynı zamanda internet, televizyon, telefon ve e-mail hizmeti verebilmekte ve bu hizmetler aracılığıyla kitap, müzik, film haber vs. gibi içeriklere ulaşılabilmektedir. Bunun dışında son kullanıcı, içerikleri mobil şebekesine sahip sektör oyuncusundan bağımsız olarak, başka bir şirketten hizmet alabilmektedir.

Çok hızlı gelişmelerin yaşandığı çapraz medya ve yakınsama sektöründe, geleneksel sınırların ortadan kalkmasıyla birlikte, özellikle etik ve hukuk yönünden sorunlar artmıştır. Verilerin üretimi, analizi ve paylaşımı noktasından başlayarak, kişisel ve kurumsal veri ve mahremiyet güvenliği alanına kadar çeşitli biçimlerde ortaya çıkan sorunlar, yakınsak ve çapraz medya stratejisine yönelik politik, hukuki ve sosyokültürel düzenlemeleri gerekli kılmaktadır (Bitirim Okmeydan, 2017: 366) . $\mathrm{Bu}$ bağlamda hem sektör oyuncularının hem de nihai kullanıcıların korunması için devletler, çeşitli organlar ya da bağımsız düzenleyici kurumları aracılığıyla düzenlemeler yapma yoluna gitmektedirler.

Telekomünikasyon sektörünü düzenleme ve denetleme fonksiyonunun bağımsız bir idari otorite tarafından yürütülmesi amacıyla, 2813 sayılı Telsiz Kanununda değişiklik yapan 27.1.2000 tarihli ve 4502 sayılı Kanunla, "Bilgi Teknolojileri Kurumu” kurulmuştur. Bu kanuna, 10.11.2008 tarihli ve 5809 sayılı "Elektronik Haberleşme Kanunu" ile birlikte yeni bir düzenleme getirilmiş ve adı "Bilgi Teknolojileri ve İletişim Kurumu” olarak değiştirilmiştir. 2813 sayılı Telsiz Kanunu ise yeni bir düzenlemeye tabii tutularak, "Bilgi Teknolojileri ve İletişim Kurumunun Kuruluşuna İlişkin Kanunu” olarak değiştirilmiştir (https://www.btk.gov.tr/kurulus). 13 Nisan 1994 tarihinde yürürlüğe konulan 3984 sayılı Radyo ve Televizyon Kuruluş ve Yayınları Hakkında Kanun ile kurulan Radyo Televizyon Üst Kurulu, Türkiye'deki yayınları denetleme, iptal etme, frekans dağıtımı gibi konularda yetkilendirilmiştir (Kuyucu, 2013: 159).

\section{SONUÇ}

Dijitalleşmenin alt yapısıyla ortaya konulan yakınsama teknolojisi ve bu teknolojinin kurumsal süreç ayağı olarak değerlendirilebilecek çapraz medya stratejileri kavramları sıklıkla kullanılmakta olsalar da; aynı biçimde anlaşılmazlar. Bu bakımdan, etimolojik farklılıktan dolayı, yakınsamayı bir olgu; çapraz medyayı 
bir strateji olarak değerlendirmek doğru olacaktır. Buna göre çapraz medya, yakınsamanın bir üst kavramı olarak karşımıza çıkmaktadır.

Çapraz medya kavramının arkasında, farklı medya içeriklerinin, birçok farklı platformlarda pazarlanmasının koordine edilmesi temel düşüncesi yatmaktadır. Çapraz medya uygulamalarının en eski örnekleri olarak, sinema filmlerinin sinemada, videolarda, televizyonda gösterimi ve aynı zamanda filmin kitabının ve müziklerinin pazarlanması gösterilebilir.

Günümüze gelindiğinde, yakınsama teknolojisinin gelişmesi ile birlikte çapraz medya kavramının içeriği oldukça genişlemiştir. Artık enformasyon, iletişim ve aktarım teknolojisi gibi tamamen farklı yeniliklerden söz edilmektedir. Örneğin Mikrosoft'un sanal gerçeklik gözlüğü (HoloLens), telefonla eşleştirilebilen akıllı saatler (AppleWatch ) gibi giydirilebilen (Wearables) teknoloji söz konusudur. Yazılı basın ürünlerinin barkod okuyucusu ile sesli hale dönüşmesi, internet ve televizyonların bir arada olduğu smart televizyonlar, 2004 yılında Facebook ile başlayan, 2006 yılında Twitter ile deavam eden, 2010 y1lında Instagram ile süren sosyal medya platformları gibi yenilikçi ürünler gün geçtikçe artmaktadır.

İçeriklerin sanal ortamlarda üretildiği, bu içeriğin dijital araçlar üzerinden ağlara ulaştığı ve bunun sonucunda oluşan veri ile işe yarar bilginin kazanıldığ yakınsama yapısı, tüm bu yenilikçi gelişmelere olanak sağlamaktadır. Yakınsama medya pazarındaki dijital anlamda köklü değişiklikleri ifade etmektedir.

Dijitalleşme temelinde yükselen çapraz medya yakınsamasının amacı, medya işletmesinin kazancının belirlenen sinerji yoluyla yükseltilmesidir. Belirlenen sinerji, marka, pazarlama, organizasyon ve pazarlama değer zinciri bakış açıları ile şekillendirilmektedir.

Çapraz medya stratejileri etrafinda dönen tartışmalar, iki ana kolda ilerlemektedir. Bunlardan biri çapraz medya yakınsamasının lehinde olan görüşlerdir. Buna göre, çapraz medya stratejileri sayesinde daha verimli pazar değerleri ortaya çıkmıştır. Büyük medya şirketleri güçlerini, daha küçük pazarlara ve daha küçük medyalara daha fazla kaynak getirme yönünde aktarmaktadır. Ayrıca pazar payını azaltan kuvvetler olarak internet, uydu televizyonu ve kablolu sistemi içeren yeni 
medyanın yaygınlaşması, geride kalanları kendisine yetişmek adına zorlamakta, bu da kaliteyi artırmaktadır.

Çapraz medya yakınsamasının aleyhinde olan görüşlerin temelinde; medyada çoklu editoryal yapının, çok sesliliğin kaybına neden olacağı düşüncesi yatmaktadır. Buna göre, medyanın az sayıda şirketin ve bireylerin ellerinde olması anlamına gelen yoğunlaşma, iletişim ve fikri hakların önünde en büyük tehlike olarak durmaktadır.

Yayın hizmetleri alanında haber alma ve ifade özgürlüğünün, rekabet ortamının, düşünce çeşitliliğinin ve çoğulculuğun güvence altına alınması ve yoğunlaşmanın önlenmesi, kamunun menfaatinin korunması gibi konular hukuki düzenlemelere gerek duymaktadır.

$\mathrm{Bu}$ amaçlarla, Radyo ve Televizyon Üst Kurulu (RTÜK) ile Bilgi Teknolojileri ve İletişim Kurumu (BTK) tarafindan, "Radyo, Televizyon ve İsteğe Bağlı Yayınların İnternet Ortamından Sunumu Hakkında Yönetmelik" hazırlanmıştır. Resmi Gazete'nin 1.8.2019 tarihli sayısında yayımlanarak yürürlüğe girmiştir (https://www.rtuk.gov.tr/duyurular/3788/7030/radyo-televizyon-ve-istegebagli-yayinlarin-internet-ortamindan-sunumu-hakkinda-yonetmelik-yururlugegirdi.html; http://www.resmigazete.gov.tr/eskiler/2019/08/20190801-5.htm).

$\mathrm{Bu}$ yönetmelikte belirtilen şartları sağlayıp, internet ortamından yayın hizmeti sunmak isteyen medya hizmet sağlayıcı kuruluşlara RTÜK tarafından verilen lisans ve yetkiler dört kategoriye ayrılmıştır: 1- radyo yayını sunmak için talepte bulunanlara internet-RD yayın lisansı, 2- televizyon yayını sunmak için talepte bulunanlara internet-TV yayın lisansı, 3- isteğe bağlı yayın hizmeti sunmak için talepte bulunanlara internet-İBYH yayın lisans1, 4- internet ortamından yayın iletim hizmeti sunmak isteyen platform işletmecisi kuruluşlara "internet ortamından yayın iletim yetkisi” belli ücretler karşılığı verilecektir.

Medya hizmet sağlayıcı kuruluşların, internet ortamından sundukları yayınlarını kablo, uydu ve benzeri ortamlardan da sunmak istemeleri halinde, her bir yayın tekniği ve ortamına ilişkin olarak ayrı ayrı yayın lisanslarını, RTÜK'ten almaları gerekecektir. 
"Radyo, Televizyon ve İsteğe Bağlı Yayınların İnternet Ortamından Sunumu Hakkında Yönetmelik” lisans alabilecek kuruluşların, kuruluş, hak ve sorumlulukları hakkında detaylı düzenlemeleri içermektedir.

Bu bağlamda, RTÜK ve BTK tarafından hazırlanıp yürürlüğe giren yönetmeliğin, bir yandan yakınsak teknoloji ve çapraz medya konusunda taşınan endişeleri, düzenleme altına alırken; diğer yandan "sansür" algısına yol açıp açmayacağı konusunda yeni tartışmaları doğurma olasılığı bulunmaktadır.

\section{KAYNAKÇA}

ATAŞ, Halide (2018). "Medya Yoğunlaşması ve Çoğulculuğun Sağlanması", Dicle Üniversitesi Adalet Meslek Yüksekokulu Dicle Adalet Dergisi, 2 (3), s.49-70. BEHMER, Markus (2015). Warum crossmedial arbeiten?, (Hrsg.), Markus Kaisser. Innovation in den Medien: Crossmedia, Storywelten, Change Management, München: Verlag Dr. Gabrielle Hooffacker, s.24-43.

BİNARK, Mutlu (2013). Yeni Medya ve Yaratıcı Endüstri, (Editörler), Erdal Dağtaş. Medya Ekonomisi ve İşletmeciliği, Eskişehir: Anadolu Üniversitesi, s.163-190.

BİTİRIM OKMEYDAN, Selin (2017). "Yeni İletişim Teknolojilerini Sorgulamak: Etik, Güvenlik Ve Mahremiyetin Kesiştiği Nokta”, Gümüşhane Üniversitesi İletişim Fakültesi Elektronik Dergisi: e-GIFFDER, 5 (1), s.347-372.

BOLAT, Nursel (2018). Ürün Yerleştirmede Kavramsal Boyutlar ve Ürün Yerleştirme Ortamları İncelemesi, (Editörler), Nursel Bolat. Teoriden Pratiğe, Spordan Medyaya Ürün Yerleştirme Uygulamaları, Konya: Literatürk, s.1343.

BTK, https://www.btk.gov.tr/kurulus, Erişim Tarihi: 8.8.2019.

CEYLAN, Reşat (2010). "Yakınsama Hipotezi: Teorik Tartışmalar”, Sosyoekonomi, 11(11), s.47-60.

EU, https://ec.europa.eu/digital-single-market/en/news/green-paper-convergencetelecommunications-media-and-information-technology-sectors-and . Erişim Tarihi: 2.11.2018. 
https://www.turkcebilgi.com/masaüstü_yayıncılık. Erişim Tarihi: 15.11.2018.

https://fizikolog.net/konular/optik-1.isik-ve-golge/mercekler.html, Erişim Tarihi: 8.8.2019.

http://www.resmigazete.gov.tr/eskiler/2019/08/20190801-5.htm. Erişim Tarihi: 8.8.2019.

KARINCA, Mürüvvet Göksu (2013). “Telekomünikasyonda Yakınsama Kavramı”, Ankara Barosu Dergisi, 4, s.263-282.

KIRAÇ, Erkan; (2018). "Dijitalleşmenin İçinde Bulunduğumuz Dünü, Bugünü, Yarını", https://medyademlik.com/dijitallesmenin-icinde-bulundugumuzdunu-bugunu-yarini/. Erişim Tarihi: 15.11.2018.

KUYUCU, Mihalis (2013). “Türkiye'de Çapraz Medya Sahipliği: Medya Ekonomisine Olumsuz Etkileri $\mathrm{Ve} \mathrm{Bu}$ Etkilerin Önlenmesine Yönelik Öneriler”, Selçuk Üniversitesi İletişim Fakültesi Akademik Dergi, 8 (1), s.144-163.

KUYUCU, Mihalis (2014). "Medya Ekonomisi Ve Başrol Oyuncuları: Bugünün Ve Yarının Medya Aktörlerinin Gözünde Reklamcılar Ve Tüketiciler”, The Turkish Online Journal of Design, Art and Communication - TOJDAC 4 (1), s. $25-35$.

MAHRDT, Niklas. (2009). Crossmedia Kampagnen erfolgreich planen und umsetzen, Wiesbaden: Gabler GWV Fachverlage.

OECD, http://www.oecd.org/officialdocuments/publicdisplaydocumentpdf/?cote=DS TI/ICCP/IE(2007)3/FINAL\&docLanguage=En . Erişim Tarihi: 8.8.2019.

ÖZEL, Sedat (2011).’Yakınsama: Yeni Medyanın İtici Gücü”, Erciyes İletişim Dergisi “akademia” 2 (2), s.54-66.

PICOT, Arnold; HOPF, Stefan; NEUBURGER, Rahild (2015). Wandel der Medienwelt als Basis von Innovationen. (Hrsg.), Markus Kaisser. Innovation in den Medien: Crossmedia, Storywelten, Change Management. München: Verlag Dr. Gabrielle Hooffacker. s.11-23. 
RTÜK, https://www.rtuk.gov.tr/duyurular/3788/7030/radyo-televizyon-ve-istegebagli-yayinlarin-internet-ortamindan-sunumu-hakkinda-yonetmelikyururluge-girdi.html. Erişim Tarihi: 8.8.2019.

SCHNEIDER, Martin; ERMES, Christoph (2013). Management von Medienunternehmen zwischen Konvergenz und Crossmedia. (Hrsg.). Martin Schneider. Management von Medienunternehmen: Digitale Innovationen Crossmediale Stretegien, Wiesbaden: Springer Gabler, s. 9-28.

TDK;(2018),'Yakınsama",

http://www.tdk.gov.tr/index.php?option=com_gts\&arama=gts\&guid=TDK.G TS.5bf131bd9a2e43.44925379 . Erişim Tarihi: 26.10.2018.

YILMAZ, Recep; ERDEM, M. Nur (2016). 150 Soruda Geleneksel Ve Dijital Reklamcılık, Kocaeli: Umuttepe Yayınları. 